\title{
UTILIZAÇÃO DE DADOS GEORREFERENCIADOS NA DETERMINAÇÃO DE PARÂMETROS DE DESEMPENHO EM COLHEITA MECANIZADA
}

\author{
JOSÉ P. MOLIN ${ }^{1}$, MARCOS MILAN ${ }^{2}$, MICHEL G.T. NESRALLAH ${ }^{3}$, \\ CESAR N. DE CASTRO ${ }^{4}$, LEANDRO M. GIMENEZ ${ }^{5}$
}

\begin{abstract}
RESUMO: As informações sobre o desempenho e a capacidade de trabalho das máquinas agrícolas são de grande importância no gerenciamento de sistemas mecanizados agrícolas, auxiliando na tomada de decisões. A obtenção de informações sobre o desempenho é normalmente realizada de modo manual, por meio da análise dos tempos e movimentos, consumindo recursos, mão-de-obra e tempo. Considerando-se a importância das informações e o custo envolvido na aquisição, o objetivo deste trabalho é apresentar uma metodologia automática para a determinação da capacidade de trabalho de colhedora de cereais. Para tanto, realizou-se o estudo de tempos e movimentos a partir de arquivos de dados obtidos por meio de monitores de produtividade em oito propriedades no Estado do Paraná. A partir dos dados coletados, calcularam-se as diferenças de tempo entre as posições da colhedora no talhão, construindo-se um mapa espacializado das diferenças. Com base no mapa de tempos, foi possível obter os mapas das capacidades de campo e processamento, além das eficiências, sendo a metodologia utilizada viável para avaliar, a partir de amostragem densa e automática, o desempenho operacional de colhedoras sem incorrer em custos adicionais para os produtores.
\end{abstract}

PALAVRAS-CHAVE: agricultura de precisão, mecanização, gerenciamento.

\section{USING GEORREFERENCED DATA FOR DETERMINATION OF HARVESTING PARAMETERS}

\begin{abstract}
The information about field efficiency and capacity of agricultural machinery is very important for the management of agricultural mechanized systems, helping supporting administration at making decisions. The information is usually obtained by manual ways using resources like, time and people. By considering the importance of the information and the cost of the acquisition, the proposal of this work was to present a methodology to determination field capacity, using information from a yield monitor. Therefore a time motion study, from data files gathered by yield monitors, during a harvester operation in eight farms in the state of Parana (Brazil) was carried out. The time difference related to the harvester in the field was calculated from the collected data and a map of the differences was developed. Using the differences it was possible to get the field efficiency, field capacity and throughput capacity maps. The suggested methodology is practicable and allows the evaluation, based on a sample that embraces many points and is automatically obtained, of the harvester with no additional expense for the farmers.
\end{abstract}

KEYWORDS: precision agriculture, mechanization, management.

\section{INTRODUÇÃO}

As técnicas de agricultura de precisão diferenciam-se dos conceitos tradicionais de agricultura pelo seu nível de gerenciamento, e o monitor de produtividade é um, dentre os muitos recursos, dos utilizados pelos agricultores que adotam essas técnicas. $\mathrm{O}$ conhecimento adquirido com as informações fornecidas pela agricultura de precisão permite aos produtores melhor suporte

\footnotetext{
${ }^{1}$ Eng$^{\mathrm{o}}$ Agrícola, Prof. Associado, Departamento de Engenharia Rural, ESALQ/USP, Piracicaba - SP, Fone: (0XX19) 3429.4165, jpmolin@esalq.usp.br

${ }^{2}$ Eng $^{\circ}$ Agrônomo, Prof. Associado, Departamento de Engenharia Rural, ESALQ/USP, Piracicaba - SP.

${ }^{3}$ Eng $^{\circ}$ Agrônomo, Avaré - SP.

${ }^{4}$ Eng ${ }^{0}$ Agrônomo, Brasília - DF.

${ }^{5}$ Eng ${ }^{\circ}$ Agrônomo, Fundação ABC, Castro - PR.
}

Recebido pelo Conselho Editorial em: 19-10-2004

Aprovado pelo Conselho Editorial em: 26-9-2006

Eng. Agríc., Jaboticabal, v.26, n.3, p.759-767, set./dez. 2006 
na tomada de decisões, resultando em potenciais benefícios ambientais, economia de insumos e lucros. Além disso, podem ser extraídas outras informações do monitor de produtividade com utilidade no gerenciamento de operações agrícolas, como a colheita.

Informações acerca da capacidade operacional são de grande importância no gerenciamento de sistemas mecanizados agrícolas, auxiliando nas decisões a serem tomadas pela administração, visando a sua otimização. A habilidade de uma máquina para desempenhar eficientemente sua função, trabalhando em qualquer ambiente, é um critério importante que afeta decisões sobre o seu gerenciamento (TAYLOR et al., 2002).

MIALHE (1974) designa a capacidade operacional de máquinas e implementos agrícolas como a quantidade de trabalho que são capazes de executar na unidade de tempo, constituindo-se em uma medida da intensidade do trabalho desenvolvido na execução das operações. $\mathrm{O}$ autor salienta que o estudo das operações visa a racionalizar o emprego das máquinas, implementos e ferramentas na sua execução. Para isso, é necessário não apenas o estudo analítico, a fim de determinar "o que fazer" e "quando fazer", mas também a criteriosa seleção de métodos, além da escolha de espécimes mais adequados a cada situação.

Considera-se importante que o desempenho das colhedoras seja otimizado por se tratar de máquinas com elevado custo operacional. Dessa forma, um método preciso de calcular o desempenho das colhedoras auxilia os usuários a selecionar corretamente a sua capacidade, bem como o equipamento requerido para o transporte da cultura.

Segundo STRICKLAND et al. (2001), no passado, os estudos de desempenho de máquinas a campo eram realizados utilizando-se de cronômetros, pranchetas e mecanismos de gravação, que consumiam muito tempo e necessitavam de uma pessoa ou uma equipe de campo para apontamentos. O advento dos monitores de colheita para fins de obtenção de mapas de produtividade tornou a coleta de dados para essa operação mais simples, utilizando um receptor de GPS ("Global Positioning System") conectado a um computador instalado na cabine da colhedora e sensores que medem o fluxo e a umidade dos grãos colhidos, definindo a produtividade na área de forma georreferenciada.

Os dados georreferenciados podem também ter papel importante na operação e no gerenciamento de máquinas agrícolas. Os dados adquiridos durante a colheita fornecem informações relativas a características operacionais da colhedora, como velocidade, percursos realizados, produtividade e tempo de descarga, bem como influências do relevo e características do operador sobre a capacidade de campo da colhedora (GRISSO et al., 2002).

Considerando as possibilidades de aplicação de monitores de produtividade em estudos na operação de colheita, o objetivo do presente trabalho foi desenvolver metodologia para a determinação do desempenho operacional espacializado de colhedoras de cereais, com base nas informações geradas nos monitores, demonstrando sua aplicação aos conceitos de eficiência apresentados na bibliografia.

\section{MATERIAL E MÉTODOS}

Utilizaram-se arquivos obtidos com monitores de produtividade advindos de talhões de propriedades pertencentes a oito produtores rurais, distribuídos entre os municípios de Castro, Carambeí e Ponta Grossa - PR, com culturas de milho e soja. Dos arquivos, três foram gerados com o monitor de produtividade FieldStar $\left(\mathrm{AGCO}^{\circledR}\right)$, instalado em colhedora marca $\mathrm{AGCO}^{\circledR}$, modelo MF 34, e cinco com o monitor PLMS New Holland (AgLeader ${ }^{\circledR}$ ), em colhedora $\mathrm{CNH}^{\circledR}$, modelo TC 57. As informações sobre as oito áreas são apresentadas na Tabela 1. 
TABELA 1. Área avaliada, colhedora utilizada e cultura presente nos oito talhões onde foram coletados os dados durante a safra agrícola de 2002.

\begin{tabular}{cccc}
\hline Talhão & Área (ha) & Colhedora (Marca/Modelo) & Cultura \\
\hline 1 & 24,5 & CNH/TC 57 & Milho \\
2 & 22,8 & CNH/TC 57 & Milho \\
3 & 16,6 & CNH/TC 57 & Soja \\
4 & 17,9 & CNH/TC 57 & Soja \\
5 & 29,3 & CNH/TC 57 & Soja \\
6 & 19,2 & AGCO/MF 34 & Soja \\
7 & 33,0 & AGCO/MF 34 & Milho \\
8 & 26,2 & AGCO MF 34 & Milho \\
\hline
\end{tabular}

Para o tratamento dos dados, utilizou-se de Sistema de Informação Geográfica SSToolbox (SST Development Group ${ }^{\circledR}$ ), planilha de cálculo do Excel $\left(\right.$ Microsoft ${ }^{\circledR}$ ) e algoritmo para a transformação das coordenadas geodésicas em coordenadas UTM. No monitor FieldStar, o tempo é armazenado no formato de horário UTC (Universal Time Coordinated), em horas, minutos e segundos, de acordo com Greenwich, enquanto o monitor New Holland PLMS utiliza o tempo na forma cumulativa em segundos, sendo o valor total zerado no último dia do ano. Devido a essa diferença, inicialmente, os dados de campo foram tratados em função do monitor que os gerou, para a eliminação de erros e valores improváveis. Para isso, utilizou-se da metodologia proposta por GIMENEZ \& MOLIN (2004), realizando-se a transformação das coordenadas geodésicas em coordenadas UTM e calculando-se a distância entre os pontos, utilizando o teorema de Pitágoras.

A partir da informação da diferença de tempo, foi possível calcular a velocidade de deslocamento entre os pontos, utilizando as distâncias percorridas e os tempos e, com esses parâmetros, analisou-se o desempenho das máquinas. Os monitores foram ajustados para a coleta de dados no intervalo de $3 \mathrm{~s}$, sendo definidas, a partir de avaliação preliminar dos dados, as seguintes classes de tempo: Tcol - tempo produtivo da máquina realizando a colheita e correspondente ao intervalo de 2 a $6 \mathrm{~s}$; Tm - tempos de manobra, no intervalo de 7 a $80 \mathrm{~s}$; Td tempos de descarga, de 81 a $420 \mathrm{~s}$; Tp - tempos-problema, maiores que $420 \mathrm{~s}$, que são aqueles tempos não ligados diretamente à operação.

A partir dos tempos de colheita, fornecidos pelo arquivo do monitor da colhedora, realizou-se o somatório dos tempos totais de cada classe de diferença de tempos, calculando-se a eficiência da operação: campo (EC), gerencial (EG) e global (EGL). Para tanto, utilizou-se das eqs.(1), (2) e (3), respectivamente, adaptadas a partir das propostas de GAGO (1986):

$$
\mathrm{EC}=\left(\frac{\mathrm{Tcol}}{\mathrm{Tcol}+\mathrm{Tm}+\mathrm{Td}}\right) 100
$$

em que,

EC - eficiência de campo, \%;

Tcol - tempo produtivo da máquina realizando a colheita, s;

Tm - tempos de manobra, s, e

Td - tempos de descarga, s.

$$
\mathrm{EG}=\left(\frac{\mathrm{Tcol}+\mathrm{Tm}+\mathrm{Td}}{\mathrm{Tcol}+\mathrm{Tm}+\mathrm{Td}+\mathrm{Tp}}\right) 100
$$

em que,

EG - eficiência gerencial, \%, e

$\mathrm{Tp}$ - tempo-problema, s.

$$
\mathrm{EGL}=\left(\frac{\mathrm{Tcol}}{\mathrm{Tcol}+\mathrm{Tm}+\mathrm{Td}+\mathrm{Tp}}\right) 100
$$


em que,

EGL - eficiência global, \%.

A EC indica o quão eficiente é o sistema no que diz respeito à influência dos tempos de manobra e descarregamento. A EG indica a influência dos tempos parados sobre a operação. A EGL indica o quanto do tempo total de campo disponível realmente está sendo utilizado para a colheita e é coincidente com a definição dada por HUNT (1995).

As capacidades de campo e de produção efetiva foram calculadas com base nos conceitos definidos por MIALHE (1974) e tendo os tempos transformados para horas:

$$
\mathrm{CcE}=\frac{3,6 \mathrm{AT}}{\mathrm{Tcol}}
$$

em que,

CcE - capacidade de campo efetiva, ha $\mathrm{h}^{-1}$, e

AT - área trabalhada, ha.

$$
\mathrm{CP}=\frac{3,6 \mathrm{QC}}{\mathrm{Tcol}}
$$

em que,

$\mathrm{CP}$ - capacidade de processamento, $\mathrm{kg} \mathrm{h}^{-1}$, e

QC - quantidade colhida, $\mathrm{kg}$.

Para o caso de máquinas de colheita, há forte dependência do estado e da produtividade do produto no desempenho da máquina e na eficiência da operação. Por isso, a capacidade de processamento expressa melhor o desempenho da máquina se comparada com a capacidade de campo efetiva.

Os resultados de velocidades, eficiências e capacidades foram expressos na forma de mapas de superfícies obtidos a partir da interpolação dos valores pontuais, utilizando o método do inverso da distância, permitindo, assim, a visualização espacializada da informação em cada talhão. Esses mesmos parâmetros foram também expressos pelas suas médias para confrontação entre as diferentes áreas, máquinas e culturas.

\section{RESULTADOS E DISCUSSÃO}

Os primeiros resultados obtidos foram os mapas de diferença de tempo que apresentam o local e as paradas ocorridas durante a colheita na área, por tempos de manobras de cabeceiras, tempos de descarregamento, paradas devido a embuchamentos da máquina, reparos rápidos, refeição, entre outras ocorrências mais esporádicas relacionadas ao operador ou à máquina. $\mathrm{Na}$ Figura 1, é apresentado, como exemplo, um dos mapas com as classes de diferenças de tempos, obtido no talhão 4.

Na Figura 2, é apresentado o mapa com as velocidades de operação da colhedora durante a colheita no talhão 1 . A investigação das causas referentes à variação espacial das velocidades de operação pode resultar na descoberta de fatores que influenciaram, pontualmente no talhão, no desempenho da colhedora e da colheita como um todo, permitindo, em determinados casos, a adoção de medidas visando a melhorar o desempenho global da operação.

Os resultados do somatório dos tempos totais de cada classe de diferença de tempos são apresentados na Tabela 2. 


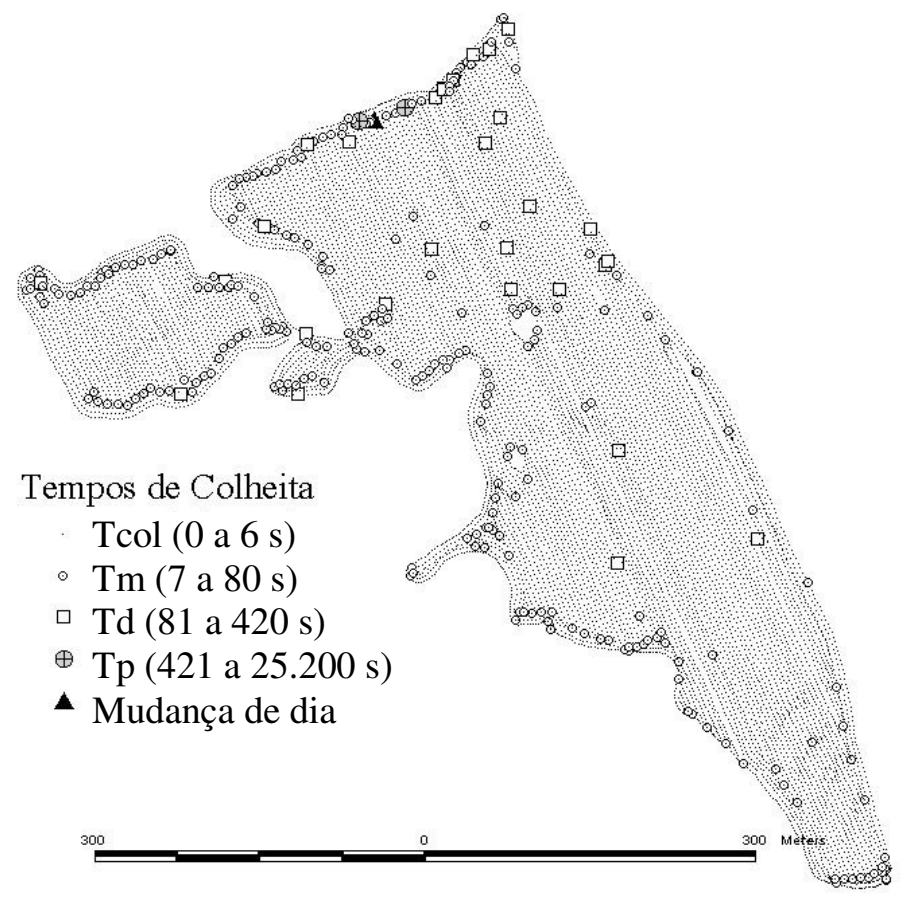

FIGURA 1. Classes de diferenças de tempos na operação de colheita no talhão 4, estabelecidos para este estudo.

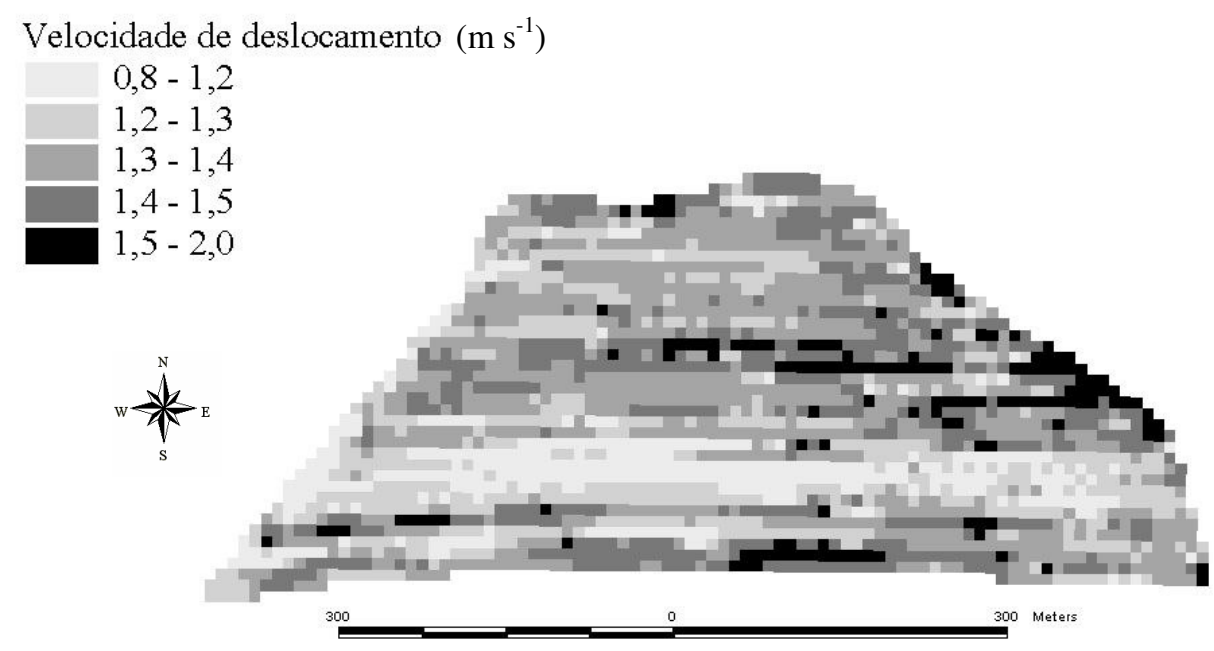

FIGURA 2. Mapa com a velocidade da operação de colheita para o talhão 1.

TABELA 2. Tempos totais durante a operação de colheita para as classes de diferenças de tempos para as áreas monitoradas no estudo.

\begin{tabular}{cccccc}
\hline \multirow{2}{*}{ Talhão } & \multicolumn{5}{c}{ Tempos da Operação (h) } \\
\cline { 2 - 6 } & Total & Colheita (Tcol) & Manobra (Tm) & Descarga (Td) & Problema (Tp) \\
\hline 1 & 24,5 & 14,0 & 2,0 & 2,1 & 6,4 \\
2 & 29,3 & 15,7 & 3,6 & 4,8 & 5,2 \\
3 & 15,2 & 10,4 & 1,7 & 1,2 & 1,9 \\
4 & 16,5 & 10,6 & 1,4 & 0,6 & 3,9 \\
5 & 18,6 & 13,8 & 1,0 & 1,6 & 2,2 \\
6 & 10,5 & 6,2 & 1,7 & 1,4 & 1,2 \\
7 & 18,4 & 12,3 & 1,1 & 2,4 & 2,6 \\
8 & 18,3 & 12,0 & 1,2 & 3,7 & 1,4 \\
\hline
\end{tabular}


Na Figura 3, são apresentados o mapa de eficiência de colheita diária do talhão 2 e os valores de eficiência para cada dia de trabalho. Os mapas dessa natureza contêm informações importantes que podem auxiliar na gerência da operação e do sistema mecanizado de uma propriedade. É possível questionar a razão das diferenças na eficiência de colheita nos diferentes dias ou nas diferentes posições ao redor da área e, a partir da identificação dos motivos, atuar na sua correção visando à otimização da colheita. No caso do talhão apresentado na Figura 3, a eficiência de colheita variou de 26\%, no dia 8-3-2002, até aproximadamente 65\%, no dia 6-3-2002. Essa simples constatação permite a percepção da importância de investigar as causas de tal variação, visando ao aumento da eficiência e, conseqüentemente, à diminuição do custo da operação.

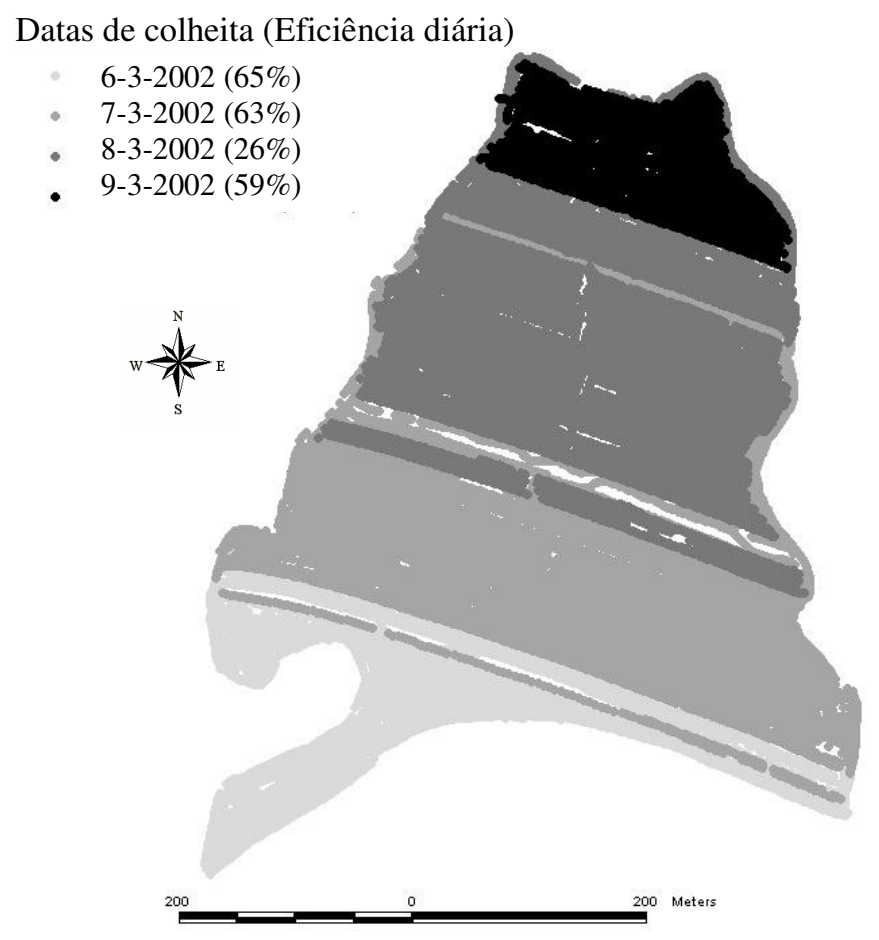

FIGURA 3. Mapa das datas e eficiências diárias de colheita para o talhão 2.

Outra informação valiosa para o gerenciamento e o dimensionamento de sistemas é que, com os dados contidos no arquivo do monitor de colheita e utilizando a eq.(4), foi possível calcular a Capacidade de Campo Efetiva (CcE). Ao contrário dos valores de eficiência, a $\mathrm{CcE}$ foi calculada de forma localizada e não-agrupada por dia da operação. Com os mesmos recursos utilizados na construção dos mapas das eficiências de colheita diárias para cada talhão, construíram-se os mapas da CcE localizada. Na Figura 4, é apresentado o exemplo de um desses mapas para o talhão 8.

Assim como a CcE é um parâmetro importante na avaliação da maioria das operações mecanizadas agrícolas, especificamente, para a operação de colheita, um segundo parâmetro muito importante é a Capacidade de Processamento (CP). Conforme WITNEY (1988), "a capacidade de processamento em tonelada por hora (ou outra forma equivalente) é, no geral, o melhor indicador do desempenho de uma colhedora, pois está relacionada com a variabilidade na produtividade da cultura. No entanto, só leva em consideração o desempenho em processar a porção comercializável da mesma". A visualização espacializada foi realizada da mesma forma que para a eficiência e para a CcE. Na Figura 5, é apresentado o mapa da CP para o talhão 6, cultivado com soja.

Os dados de diferenças de tempos durante a operação de colheita são apresentados de forma localizada nos talhões. Esses mapas, conjugados com outras séries de dados de fatores correlacionados que influenciaram nos parâmetros de desempenho das colhedoras (produtividade, presença de manchas de plantas daninhas, topografia, formato do talhão, tamanho do talhão...), oferecem vantagens no gerenciamento dos sistemas mecanizados de colheita, permitindo a geração de informação espacializada no talhão sobre o desempenho da operação. 


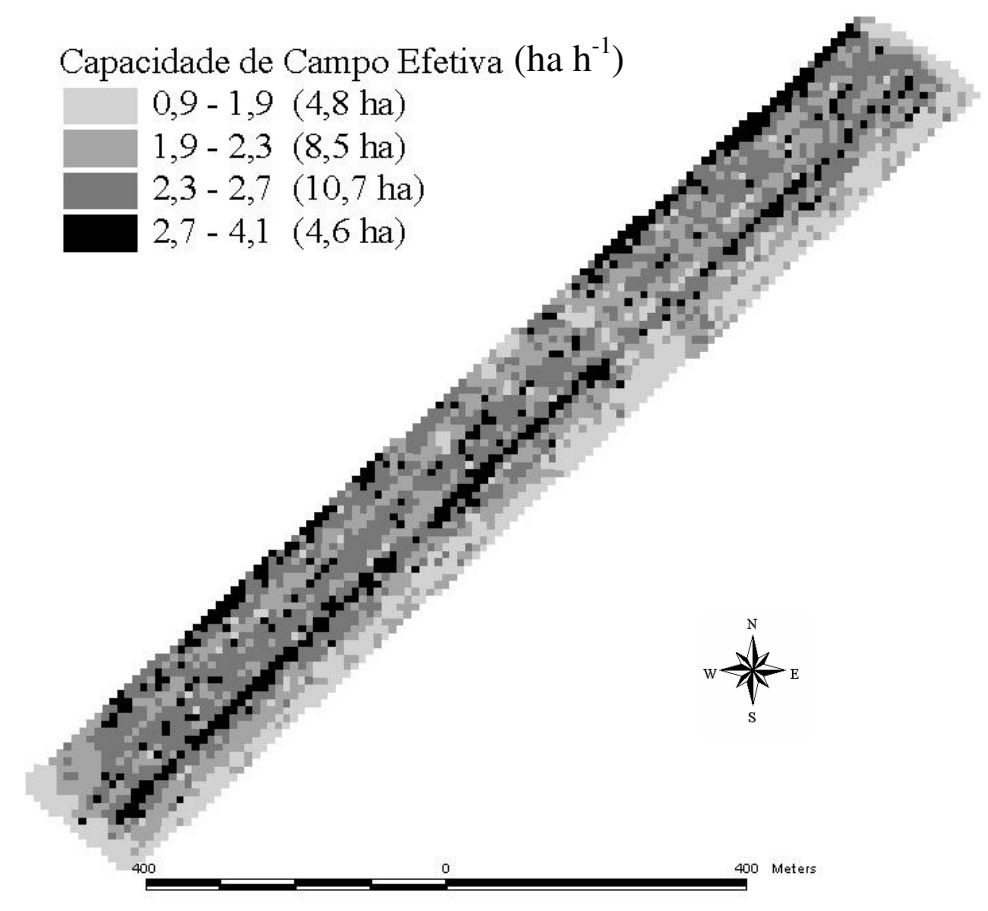

FIGURA 4. Exemplo da capacidade de campo efetiva (CcE) localizada da operação de colheita no talhão 8.

Além disso, a forma de determinação de parâmetros de desempenho utilizando dados georreferenciados provenientes do monitor de produtividade pode ser estendida a outras operações agrícolas, como a semeadura ou aplicação de defensivos, bastando, para isso, dispor de um coletor de dados conectado a um receptor de GPS, capaz de armazenar a posição geográfica e o respectivo horário. O trabalho de GRISSO et al. (2000) contempla essa idéia aplicada à operação de semeadura.

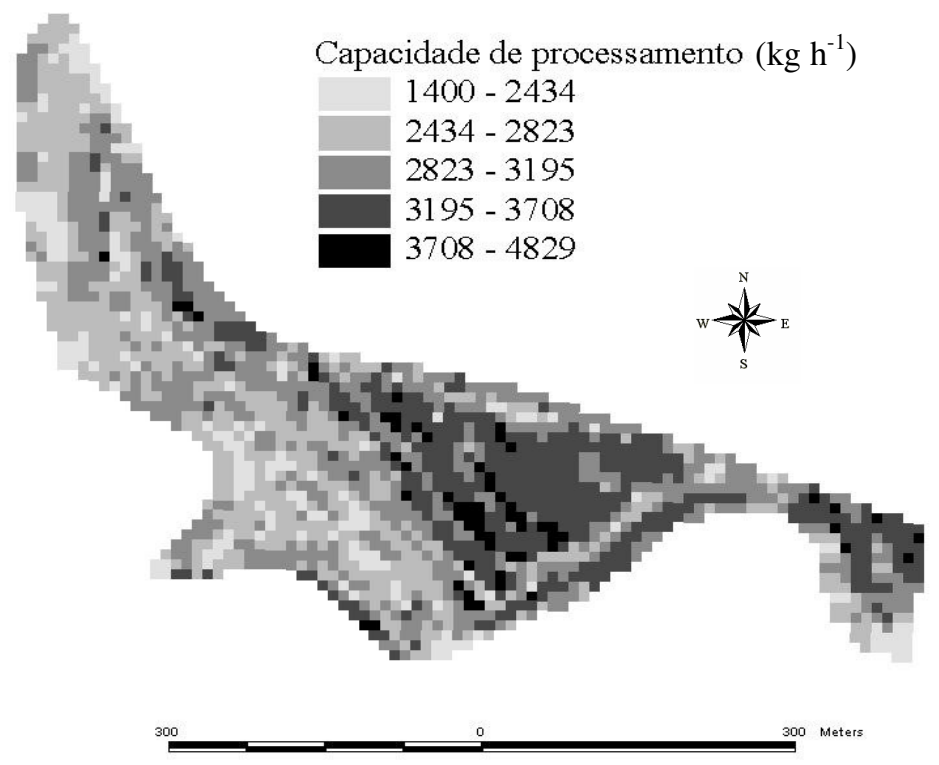

FIGURA 5. Mapa da capacidade de processamento (CP) localizada da operação de colheita para o talhão 6.

A forma de captar e descrever esses conjuntos de dados espacializados do desempenho de máquinas agrícolas, com o objetivo de organizar os mesmos e extrair informações úteis, voltadas ao gerenciamento de um sistema, pode incorporar elementos da estatística descritiva ou da geoestatística, que trata da descrição de conjuntos de dados que apresentam dependência espacial. Como exemplo, na Figura 6, utilizou-se de um histograma para descrever a distribuição de frequiências da CcE do talhão 8, que é apresentada espacializada no mapa da Figura 4. 
No histograma apresentado na Figura 6, observa-se a existência de dois picos na distribuição dos valores da $\mathrm{CcE}$, o que indica não ser uma distribuição normal e, sim, distribuição bimodal, com grande concentração em torno de dois valores. Entre outros fatores, a possibilidade da existência de duas populações distintas no conjunto de dados, devendo ambas serem analisadas em separado, pode ser uma explicação. Analisando o mapa da Figura 4, do mesmo talhão de onde foram extraídos os dados da Figura 6, observa-se, na parte superior do talhão, nítida tendência de concentração de valores elevados de CcE adjacente a uma também nítida concentração de baixos valores de CcE. Essas observações podem ser uma explicação para a existência de dois picos de valores de CcE no talhão, indicando a existência de duas regiões distintas no que se refere a esse parâmetro. A próxima etapa na análise desse conjunto de dados seria a análise, em separado, de ambas, buscando-se identificar as causas.

Na Tabela 3, são apresentados os resultados médios das três eficiências para os oito talhões avaliados neste estudo, sendo apresentados, também, os valores médios da capacidade de campo efetiva e da capacidade de processamento.

Com os valores das três eficiências para os oito talhões, observa-se que, nas três categorias, ocorre variação máxima de $19 \%$ entre os talhões. Entre os inúmeros fatores que poderiam causar essa variação, um dos mais evidentes poderia ser a influência da produtividade e da sua variabilidade espacial para as culturas sendo colhidas. Além disso, o formato dos talhões, as variações topográficas e outros fatores podem afetar o desempenho e a eficiência da operação. No entanto, agrupando os valores das eficiências em dois grupos distintos, um onde a cultura colhida foi soja e no outro, milho, e realizando-se análise de variância, nenhuma diferença foi encontrada para nenhuma das três categorias de eficiência, para significância de 5\%. Já a capacidade de campo efetiva $(\mathrm{CcE})$ e a capacidade de processamento $(\mathrm{CP})$ diferiram significativamente e pode-se observar que essa última é da ordem de três vezes maior numericamente para a cultura do milho que para a soja, fato explicado pela elevada produtividade do milho nos talhões estudados.

A metodologia desenvolvida resultou na geração de um conjunto de informações valiosas, voltadas para o gerenciamento do sistema de colheita de uma propriedade. Para o caso da operação de colheita, os parâmetros de desempenho puderam ser obtidos de dados coletados numa amostragem densa e representativa de todo o talhão, com o benefício de essa informação ser fornecida sem custo e tempo de coleta de dados adicionais para os produtores que já dispõem dos monitores de produtividade.

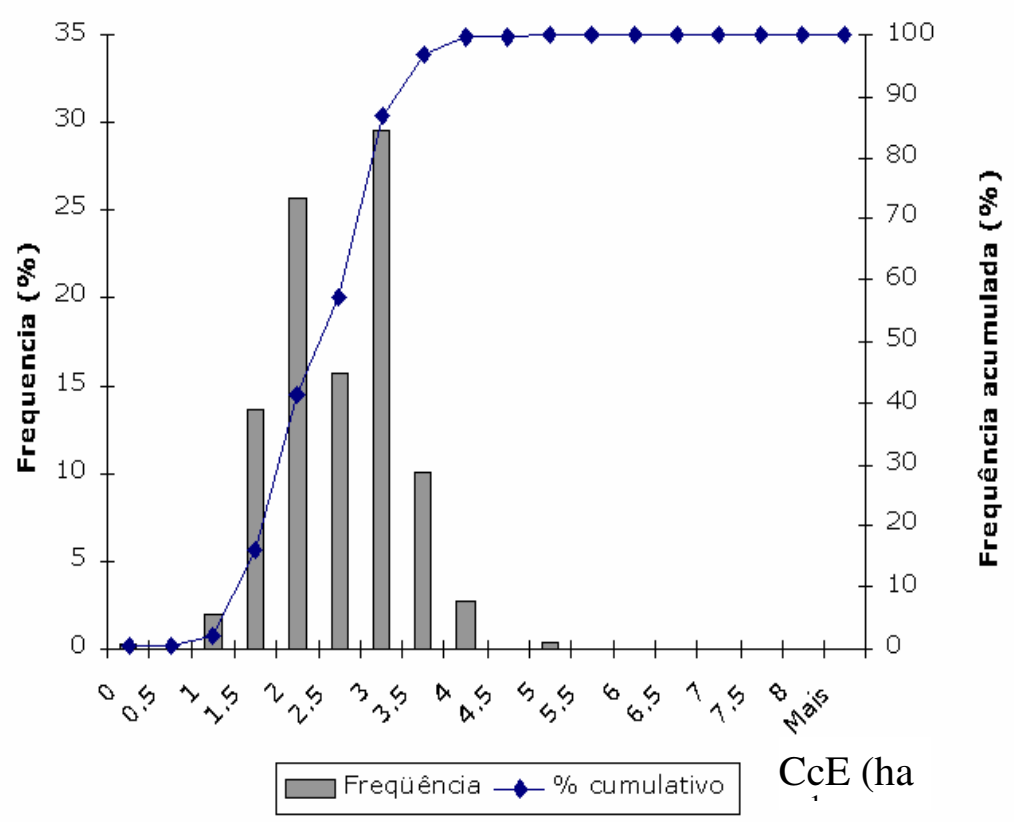

FIGURA 6. Distribuição de freqüências da CcE no talhão 8. 
TABELA 3. Valores médios da eficiência de campo (EC), eficiência gerencial (EG), eficiência global (EGL), média da capacidade de campo efetiva $(\mathrm{CcE})$ e média da capacidade de processamento $(\mathrm{CP})$ para a operação de colheita dos oito talhões experimentais.

\begin{tabular}{ccccccc}
\hline \multirow{2}{*}{ Área } & \multirow{2}{*}{ Cultura } & \multicolumn{3}{c}{ Eficiências (\%) } & \multicolumn{2}{c}{ Capacidade } \\
\cline { 3 - 6 } & & EC & EG & EGL & CcE $\left(\mathrm{ha} \mathrm{h}^{-1}\right)$ & $\mathrm{CP}\left(\mathrm{t} \mathrm{h}^{-1}\right)$ \\
\hline 1 & Milho & 77 & 73 & 52 & 1,5 & 17,0 \\
2 & Milho & 65 & 82 & 53 & 1,4 & 17,0 \\
3 & Soja & 78 & 87 & 68 & 1,9 & 4,5 \\
4 & Soja & 83 & 76 & 64 & 1,7 & 6,5 \\
5 & Soja & 84 & 88 & 74 & 2,1 & 5,0 \\
6 & Soja & 66 & 89 & 59 & 2,7 & 9,2 \\
7 & Milho & 78 & 86 & 67 & 1,4 & 28,2 \\
8 & Milho & 71 & 92 & 65 & 2,2 & 17,7 \\
\hline
\end{tabular}

\section{CONCLUSÕES}

Parâmetros de desempenho da colheita, como capacidade de campo efetiva, capacidade de processamento e eficiência da operação, foram obtidos a partir de amostragem densa e representativa de todo o talhão, sem custo adicional para os produtores que dispõem dos monitores de produtividade. Análises específicas podem auxiliar a explicar as variações localizadas dos parâmetros da colheita dentro de um talhão, além do que, a mesma metodologia pode ser utilizada com equipamentos similares aos desta pesquisa em estudos de tempos e movimentos de outras operações agrícolas.

\section{REFERÊNCIAS}

GAGO, J.S.N. Corte, carregamento e transporte de cana-de-açúcar: comparação de sistemas alternativos. In: SEMINÁRIO DE TECNOLOGIA AGRONÔMICA, 4., 1988, Piracicaba. Anais... Piracicaba: COPERSUCAR, 1986. p.431-92.

GRISSO, R.D.; JASA, P.J.; ROLOFSON, D. Field efficiency determination from spatial data. St. Joseph: ASAE, 2000. 12 p. (ASAE Paper, 001013).

GRISSO, R.D.; JASA, P.J.; ROLOFSON, D. Analysis of traffic patterns and yield monitor data for field effciency determination. Applied Engineering in Agriculture, St. Joseph, v.18, n.2, p.171-8, 2002.

HUNT, D. Farm power and machinery management. Ames: Iowa State University Press, 1995. 292 p.

MIALHE, L.G. Manual de mecanização agrícola. São Paulo: Agronômica Ceres, 1974. 301 p.

GIMENEZ, L.M.; MOLIN, J.P. Algoritmo para redução de erros em mapas de produtividade para agricultura de precisão. Revista Brasileira de Agrocomputação, Ponta Grossa, v.2, n.1, p.5-10, 2004.

STRICKLAND, R.M.; ESS, D.R.; PARSONS, S.D.; CRISLER, M.T. Extracting machine perfomance information from site-specific grain yield data to enhance crop production management practices. Net, Jul. 2001. 3p. 2001. Disponível em:

<http://mollisol.agry.purdue.edu/ssmc/newsletters/july2001f.htm>. Acesso em: 15 abr. 2002.

TAYLOR, R.K.; SCHROCK, M.D.; STAGGENBORG, S.A. Extracting machinery management information from GPS data. St. Joseph: ASAE, 2002. 9 p. (ASAE Paper, 021008).

WITNEY, B. Choosing and using farm machines. Essex: Longman Scientific \& Technical, 1988. $412 \mathrm{p}$. 